\title{
Digital Platform for Circular Economy in AEC Industry
}

\author{
Iva Kovacic ${ }^{1 *}$, Meliha Honic ${ }^{2}$, and Marijana Sreckovic ${ }^{3}$
}

\begin{abstract}
The construction industry is one of the world's largest consumers of resources (sand, building materials) and produces significant amounts of waste. Simultaneously it is one of the least digitalized industries. With increasing levels of urbanization, scarceness of resources and lack of landfills, the policy of circular economy $(\mathrm{CE})$ is becoming increasingly important in the construction industry. The European Union is obliging material recovery of construction and demolition waste to a minimum of $70 \%$ by weight by 2020 for all new construction projects. Simultaneously, digitalization in construction is one of the major goals in the EU digitalization action plan.

We thereby hypothesize that digital technologies have significant potential to support CE in Architecture, Engineering and Construction (AEC) in multiple ways - for assessment of resources as well as for the prediction and optimization of upcoming waste and recycling masses. Based on our conducted and ongoing research projects - BIMaterial: Process-Design for a BIM-based Material Passport; SCI_BIM: Scanning and data capturing for the Integrated Resources and Energy Assessment using Building Information Modeling; and finally a Case Study reviewing digital tools and processes within a large design and planning company (DPC) - we assess to which degree and to what purpose digital technologies are used, and define the potentials and challenges for the realization of CE objectives in the construction industry.

Based on the conducted assessment, we propose a framework for a Digital Platform for Circular Economy (DEEP), integrating various stakeholders and data repositories on the external (inter)-firm and internal (intra)-firm level, using open interfaces. Such a platform for the AEC aims to optimize the use of resources in the circular economy - from cradle to grave, foster mutual learning and coordination, and finally generate added value along the life cycle of a building project.
\end{abstract}

\section{Keywords}

BIM, Material Passport, Eco-Indicators, Resources, Modeling, Urban Mining

\footnotetext{
$1 *$ Professor, Institute of Interdisciplinary Construction Process Management, Vienna University of Technology, Austria, Phone +43 (1) 58801 21526, iva.kovacic@tuwien.ac.at, iva.kovacic@tuwien.ac.at (Corresponding Author) ${ }^{2}$ Project Assistant, Institute of Interdisciplinary Construction Process Management, Vienna University of Technology, Austria, Phone +43 (1) 58801 21543, meliha.honic@tuwien.ac.at

${ }^{3}$ Senior Scientist, Institute of Interdisciplinary Construction Process Management, Vienna University of Technology, Austria, Phone +43 (1) 58801 21525, marijana.sreckovic@tuwien.ac.at
} 


\section{Introduction}

The global material resources consumption is increasingly rising as well as the world's population - the future challenge will be to provide sufficient land, material and natural resources; as well as to deal with upcoming waste (Cossu et al., 2015). This increased building activity will lead to an elevated consumption of raw materials and to a significant upcoming of waste.

Building stocks and infrastructures are the largest material stock of industrial economies. It is oflong-term importance to maintain or recycle these urban stocks, and in consequence to minimise the use of primary resources and hence environmental impacts. Designing effective recycling strategies, including concepts and technologies, is required for the realisation of a pronounced circular economy in Architecture, Engineering and Construction (AEC). Often referred to as "Urban Mining", these strategies would significantly reduce the consumption of primary resources, environmental emissions and the generation of waste that has to be landfilled (Baccini and Brunner, 2012).

Currently, the traditionally conservative AEC industry is experiencing a rapid digital transformation. Digital technologies are revolutionising collaboration and value co-creation across these traditional industry boundaries, thus offering large potentials for the achievement of a circular economy in the construction sector. Nevertheless, despite the extensive integration of digital tools and technologies, which would require innovation of practices, the AEC industry tries to apply new technologies within the conventional processes, thereby lacking complete achievement of the expected economic, technical and processual benefits that new technologies offer. The highly fragmented and heterogeneous AEC industry applies the concept of digital building information modelling and management (BIMM) as one of the most spread new designing and construction methods used. However, the problem of a varying and sometimes even conflicting BIM understanding reflects various requirements and mind-sets of numerous professional domains in the AEC industry, such as e.g. exclusive focus on modelling on geometry (without enrichment of non-geometrical properties) or intra-firm instead of inter-firm data exchange and knowledge generation processes (Jung and Joo, 2011; Singh et al., 2011).

A holistic framework that would allow for continuous data and information flows (without misinterpretation or losses) as well as data processing is lacking, however needed for a) the generation of knowledge and innovation in the digital ecosystem along the life cycle and $b$ ) assessment of the environmental performance of buildings, including circular economy aspects. Such a framework would offer structured and open data exchange formats for the enhancement of productive processes, including improved engineering, procurement, and supply chain management; finally resulting in the creation of new business models and thus innovation in AEC industry.

The principle of modularity applies to Digital Platforms for Circular Economy (CE) in AEC on the external (inter-)firm as well as on the internal (intra-)firm level.

Based on our previous research conducted within the funded research projects BIMaterial and SCI_BIM, as well as empirical research of intra-firm digital platforms within a Design and Planning Company (DPC), we propose the conceptual framework for a Digital Platform for Circular Economy in the AEC Industry (DEEP) that would allow:

- widespread use of Building Information Modelling and BIM-based Material Passports (MP), as fundaments for a secondary raw materials cadaster and thus CE,

- information sharing on material resources and their life cycle data,

- information sharing on recycling and reuse of materials, and

- creation of a collaborative environment for stakeholders along the value-chain manufacturers, designers, construction companies, owners and facility managers.

The Digital Platform for Circular Economy in the AEC Industry (DEEP) is an example of an interfirm platform, where a number of particular process stakeholder modules needs to be coupled to the 
platform. Thus, for the proposal of a conceptual framework for DEEP, coupling and integration of eco-repository data, manufacturers' environmental product declaration and BIM relevant objects properties, as well as digitised public policy regulations, need to be organised into a generic structure, allowing data exchange along the life cycle.

This paper is organised as follows: First, we introduce circular economy in construction, including relevant stakeholders, data models and repositories, as well as the concept of digital platforms offering possibilities for collective value creation along the life cycle for the enhancement of CE. In further chapters we present the hypothesis and conduct the assessment of our proposed research questions based on three research projects: BIMaterial, SCI_BIM as representatives of an inter-firm, and a case study of a design and planning company (DPC) as the example of an intra-firm digital ecosystem. Finally, we present a proposal of a Digital Platform for CE coupling the inter- and intra-firm digital ecosystems, and discuss the properties of the proposed framework.

\section{Circular Economy}

Circular economy (CE) is increasingly gaining importance in governance and legislation of the European Union (EU) as well as in various business practices around the world (Korhonen et al., 2018). $\mathrm{CE}$ has its roots in the industrial revolution, where long-term damage was caused through exploitation of resources and ignorance of environmental limits (Prieto-Sandoval et al., 2018). Through new manufacturing methods, mass production of goods was enabled, which led to huge solid waste generation due to traditional linear extract-produceuse-dump processes (Frosch and Gallopoulos, 1989; Lieder and Rashid, 2016). Additionally, the growth of the world population expanded the demand for resources, wherefore first solutions for minimising the raw materials consumption were introduced by Meadows et al. (1972). In contrast to the linear economy, the circular economy concept emphasises the importance of material reuse, remanufacturing, refurbishment, repair, cascading and upgrading (EMAF - Ellen MacArthur Foundation, 2013). The aim of circular economy is to maintain the value of products, materials, and resources in the economy as long as possible in order to reach a low carbon and resource efficient economy (COM (European Commission), 2015). According to the European Commission, circular economy type economic transitions could lead to annual economic gains up to 600 billion euros in the EU manufacturing sector (COM (European Commission), 2015; EMAF - Ellen MacArthur Foundation, 2013).

\section{Circular Economy in the Construction Sector}

The construction sector is the largest consumer of raw materials (WEF - World Economic Forum, 2016). $60 \%$ of the raw materials extracted from the lithosphere (Zabalza Bribián et al., 2011) and $40 \%$ of $\mathrm{CO}_{2}$ emissions (WGBC - World Green Building Council, 2016) are caused by worldwide civil works and building constructions. $\mathrm{CE}$ emphasises the minimization of material resources consumption, waste generation as well as environmental pollution and is a promising solution to the wasteful production processes. The European Union's action plan for CE aims to minimise environmental impacts and energy consumption caused by extraction of primary materials, as well as to reduce waste through maximisation of recycling rates (COM (European Commission), 2015). The circulation of resources within the loop would consequently reduce the need for virgin materials (Andersen, 2007). One strategy to keep resources within the loop is Urban Mining. Urban Mining includes in contrast to recycling, the exploration and observation of materials in buildings and infrastructure as well as mining of waste (Klinglmair and Fellner, 2010). The main requirement to enable Urban Mining, is the availability of material information of buildings (Brunner, 2011), which is mostly not the case for the existing stock. The EU-funded Horizon 2020 project BAMB (BAMB - Buildings as Material Banks, 2016) aims at the implementation of CE in the AEC industry through e.g. MPs. MPs describe the characteristics of materials in products and buildings and are an essential instrument for implementation of the Urban Mining strategy in the construction sector. Another method supporting $\mathrm{CE}$ is Life Cycle Assessment (LCA). Through 
an LCA the flows of resources and materials are aggregated and analysed throughout the whole life cycle in order to assess and optimise the environmental impact (International Organization for Standardization, 2006a).

\section{Stakeholders involved in the implemen- tation of CE-strategies in the construc- tion sector}

In a previous study Honic et al. (2019) identified the main stakeholders involved in the implementation of MPs, which represent a main instrument for the enhancement of $\mathrm{CE}$ in the construction sector. Through the application of BIM-based MP on various use cases as well as through interviews with partners within the research project consortium (demolition companies, material industry, planners and construction companies) the stakeholders relevant for the creation of a MP and the implementation of CE-strategies were defined. Designers, planners, construction companies and MP consultants, which are summed up as "AEC organisation", are crucial decision makers regarding material composition of buildings and therefore could enhance the use of materials with high recycling potential and low environmental impact. Eco-inventories and environmental product declarations for materials and building elements needed for LCA and MP are provided by manufacturers ("industry") who therefore represent another important set of stakeholders. Regulative bodies carry great responsibility, through standardisation processes and regulations of e.g. emissions and recycling rates. Governmental or institutional agencies are thereby important digital LCA or recycling data providers. The European Commission calls for an increase of recycling and other material recovery of construction and demolition waste to a minimum of $70 \%$ by weight by 2020 (European Union, 2011). This kind of regulations could accelerate the implementation of CE solutions.

Therefore, as the three most important stakeholder sets for implementation of $\mathrm{CE}$ in the construction sector can be listed:

- AEC organisations (designers, architects, planners, MP consultants)

Engineering Project Organization Journal

(C) 2020 Engineering Project Organization Society

www.epossociety.org
- Industry - material and product manufacturers

- Regulative bodies and Public Policy

\section{Data repositories}

In order to increase resource efficiency in AEC, thus minimising resources consumption and emissions and increasing recycling rates, adoption of LCA or MPs for buildings is necessary already in early design stages. LCA, MP assessment and optimisation tools are based on reliable data regarding material information, eco-indicators, and data on recycling potential. This specific information is available from various national or international digital data repositories such as e.g. Austrian baubook by IBO (Austrian Institute for Building and Ecology), ÖKOBAUDAT (2019), or in the Environmental Production Declaration (EPD) provided directly by manufacturers following the ISO 14025 "Environmental labels and declarations" (International Organization for Standardization, 2006b).

In general, the required information for LCA and MPs can be summed up as (Honic et al. (2019)):

- Data for recycling and LCA, which can be obtained from eco-inventories

- Material composition of building elements, which are available in building elements catalogues

- Environmental Product declarations, which are offered by the product manufacturers

Currently, eco-inventories seldom provide data in a standardised, structured format, nor is an automatic data transfer via open interfaces possible yet, which makes the process tedious, requiring manual handling, thus error prone. The tedious data handling in terms of accessibility and assessment is related to significant time efforts and resources which represents a major obstacle for the implementation of CE objectives in AEC. Moreover, the units, in which data is provided as well as the nomenclature vary from database to database, leading to inconsistencies and incoherent results.

\section{Building Information Modeling (BIM)}

BIM is a shared knowledge resource consisting of information about a facility, representing a basis 
for decisions throughout the whole life cycle from the conceptual phase to the demolition of a facility (buildingSMART (2019), 2019). By international standards a BIM (here: Building Information Model) is defined as "a shared digital representation of physical and functional characteristics of any built object...", which is created with objectoriented software, consisting of parametric objects that represent building components (International Organization for Standardization, 2010; Volk et al., 2014). BIM stands for both, the model itself - the Building Information Model, or for the process Building Information Modelling (Lévy, 2011). In this paper, the term BIM will be used for Building Information Modelling, whereas for the Building Information Model "BIM-model" will be used. A BIM-model comprises information about the geometry, spatial relationships, quantities and properties of building elements as well as cost estimates and material inventories, thus containing relevant data, which is required for design, fabrication and construction activities (Bazjanac, 2004; Eastman et al., 2011). The use of BIM for design optimisation regarding resources efficiency as well as for design for deconstruction concepts is getting attention in the AEC industry, as Rajendran and Gomez (2012) found. Basbagill et al. (2013) developed a BIM-enabled decision support method for early design stages in order to carry out an LCA. However, a fully automated exchange between BIM and LCA applications is still not developed, as Soust-Verdaguer et al. (2017) identified by analysing BIM-based LCA methods for buildings. In order to create a MP and to conduct an LCA, data regarding material information, eco-indicators, etc. is necessary. Some BIM-based object libraries promise to provide relevant information for the design stage and deal with the standardisation of materials, such as the Library (2019) or BIMobject (2019). However, material information conforms either only to national standards or to intra-firm regulations, wherefore their applicability in the international BIM community is limited.

\section{Digital Platforms}

In literature there is a vast number of definitions and views on platforms: according to the economic perspective, platforms are seen as markets creating network effects through the exchanges of goods, services, money or social currency (Parker et al., 2016); in the engineering design perspective, platforms are viewed as layered modular systems with standardised interfaces or design rules enabling interoperability between modules (Baldwin and Woodard, 2009; Yoo et al., 2010); and conceptualised through the organisational perspective, technological platforms are evolving organisations or meta-organisations with a focus on agency and structure (Gawer, 2014). Metaorganisation is the specific relational way of organising legal autonomous entities, weather its firms in a network or individuals, without the use of authority characteristic to employment contracts (Gulati et al., 2012).

Platforms appear in different organisational settings, within the firm, across supply-chains and industry ecosystems. They should offer a needed solution for a broader technological system and solve a business problem for many firms and users in the industry (Gawer and Cusumano, 2014).

In the AEC industry, there are numerous uses for platforms such as for document-based collaboration and documentation across AEC disciplines and supply-chains, web- or cloud-based management of team collaboration in design and construction projects (Singh et al., 2011), electronic procurement along the AEC value chain (Grilo and Jardim-Goncalves, 2010), exchange of domainspecific model data on open or closed BIM-servers, web-based virtual reality cloud platforms for integrated AEC projects (Goulding et al., 2014), or user-centred knowledge-management platforms (Rezgui and Meziane, 2005). Nevertheless, platforms aiming for collaboration for collective value creation and knowledge management along the value chain in AEC - from cradle to grave for $\mathrm{CE}$ - are still missing. With the proposed framework in this paper we aspire to close this gap.

For the purpose of our research, we first conceptualise the platform as a digital ecosystem. Ecosystem refers in general to a group of interacting firms or modules that depend on each 
other's activities, whereas a platform ecosystem is the organisation of stakeholders around a platform (Jacobides et al., 2018). The concept of a platform within an ecosystem generates a possibility for collective value creation structured along technological trajectories and is defined "as products, services, or technologies... which provide a foundation upon which outside firms [organised as "business ecosystems"] can develop their own...products, technologies, or services" (Gawer and Cusumano, 2014).

Secondly, we take the perspective of technological platforms, with loosely coupled modular organisations (Sanchez and Mahoney, 1996) and interconnected processes for selforganisation, problem solving, innovation, flexibility, and value creation.

Thirdly, we assume the view of an external (industry) platform (Gawer, 2014) defined as an ecosystem with open interfaces - where interface specifications are shared with users, stakeholders, organisations and institutions, enabling a potentially unlimited pool of external capabilities and are coordinated through ecosystem governance. Finally, for the purposes of this paper, we expand the definition by Selander et al. (2013) and define digital ecosystems as a collective of firms and/or stakeholders that is inter-linked by a common interest in the collective value creation along the life cycle for the enhancement of $\mathrm{CE}$, and in co-alignment with those aims applying digital technology for the achievement of product, service or innovation objectives.

Therefore, in this proposal we understand the concept of the Digital Platform for Circular Economy (DEEP) as both a technological and economic construct; inter-connecting stakeholders, organisations (AEC companies) and metaorganisations (institutions), in order to generate added value along the life cycle of a building project, but also to generate benefits for the society through the implementation of CE aims. This complex interactions on several levels are enabled through coupling of digital design technologies and data repositories, which again enable modelling and optimisation of resources consumption from cradle to grave.

\section{Scope of Reseach}

We hypothesise, that digital technologies as well as broad adoption of digital planning methods and tools along the value chain play a crucial role for embracing $\mathrm{CE}$ objectives in construction. Digitalization along the value chain will enable assessment of existing stocks in terms of urban mining as well as predictive modelling and simulation of upcoming material flows; as well as design optimisation in terms of design for deconstruction and reuse, supporting the overall goal of minimization of resources consumption, upcoming of waste and emissions. In that context, we propose the Digital Platform for Circular Economy (DEEP) as an integrative framework of various stakeholders and data repositories along the value chain, on an inter- and intra-firm level, for the achievement of CE objectives.

Thereby we address the following research questions:

- Which technologies and to which degree offer potential for $\mathrm{CE}$ in construction?

- How usable are these technologies for the current AEC practice?

- What are the major challenges and obstacles for broader adoption?

The hypothesis will be examined using conducted and ongoing research projects: BIMaterial: Process-Design for a BIM-based Material Passport; SCI_BIM: Scanning and data capturing for Integrated Resources and Energy Assessment using Building Information Modelling, as well as a Case Study of a digital ecosystem within a large Austrian design and planning company - DPC.

In BIMaterial we developed a workflow for the semi-automated generation of BIM-supported MPs, focusing on new construction (Kovacic and Honic, 2018). Further on, a framework for governance and management of MPs, as instruments for the enhancement of CE in construction, based on the institutional theory was proposed. Thereby the following central stakeholders were identified: AEC, industry, and regulative bodies (public policy) as those responsible for the implementation, governance, and data management (Honic et al., 2019). 
SCI_BIM expands the framework of BIMbased MPs, focusing on the assessment of geometry, material and energy of existing building stocks using ground penetrating radar (GPR) and laser scanning. Through the applied gamification concept, users are also involved in capturing both building energy performance as well as building adaptations throughout the operational phase (Honic and Kovacic, 2019).

BIMaterial focuses on digital tools for designoptimisation of new construction, whereas SCI BIM on technologies for the assessment of existing buildings. Thereby both research projects focus on the interaction of various inter-firm digital data management and stakeholder constellations and requirements, whereas the Case Study DPC examines the digital intra-firm organisation and the potentials for data-exchange on the intra-firm level.

\section{Digital Tools for Design Optimization: BIM supported MPs}

European AEC industry consumes a significant rate of materials such as steel, aluminium, copper, and plastics, thus creating a large reservoir on secondary raw materials in buildings. One of the main strategies of the EU is to maximise recycling rates in order to minimise environmental impacts and the energy consumption caused by extraction of primary materials. To enable circularity, and in consequence high recycling rates, information about the existing stock is necessary.

The early design stages play a crucial role in waste reduction, the reusability of building elements as well as in the increase of the recycling potential. New digital design tools such as BIM enable data management along the life cycle, thus bearing large potentials for generating an MP.

Within the funded research-project BIMaterial a framework for a BIM-supported generation of MPs, based on a digital tool chain was developed (Honic et al., 2019). This project is a central milestone towards standardised, BIM-generated MP. In this project, we developed a concept for the compilation of the MP, as well as a workflow for the semi-automated generation of a MP by coupling BIM to the material inventory and analysis tool BuildingOne and eco-inventory databases (Figure 1). The proposed methodology allows for assessment of embedded materials in building design as well as simultaneous LCA, allowing assessment of Primary Energy Intensity (PEI), Global Warming Potential (PEI) and Acidification Potential (AP) as three most significant ecoindicators.

Thereby both - the potentials of BIM for the automated compilation of MPs as well as the potential of MPs as an instrument - designoptimisation tool, material inventory and as a document on material assets of real estates or building stocks along a building's life cycle, were demonstrated.

\section{Digital Tool Chain for Assessment of Building Stocks: SCI_BIM}

The ongoing research within the multidisciplinary funded research project SCI_BIM, aims to increase both resources and energy efficiency of existing building stocks through coupling of technologies and methods for capturing and modelling (as-built BIM-model with geometry and material composition) of buildings and assets, and finally using a gamification concept for the as-built model management by users. Thereby the framework for the generation of BIM-based MPs, developed in BIMaterial, is applied for the modelling and documentation of material composition of existing stocks.

The Integrated Data Assessment and Modelling Method (Figure 2) was developed and tested on a real use case of an existing university building. The capturing of geometry is carried out via laser scanning and photogrammetry, the capturing of material composition via Ground Penetrating Radar (GPR). Algorithms are developed for the semiautomated generation of the as-built BIM-model geometry from the obtained point cloud data. In a further step, the as-built models are enriched by the material information as assessed by the GPR, which allows efficient generation of MPs. Finally, this as-built BIM-model will be used for energy modelling (BEM) and energy simulation.

The conducted material assessment via GPR and the semi-automated Scan to BIM process generation of the as-built BIMs on the basis of scan data (point clouds, material information) - have 


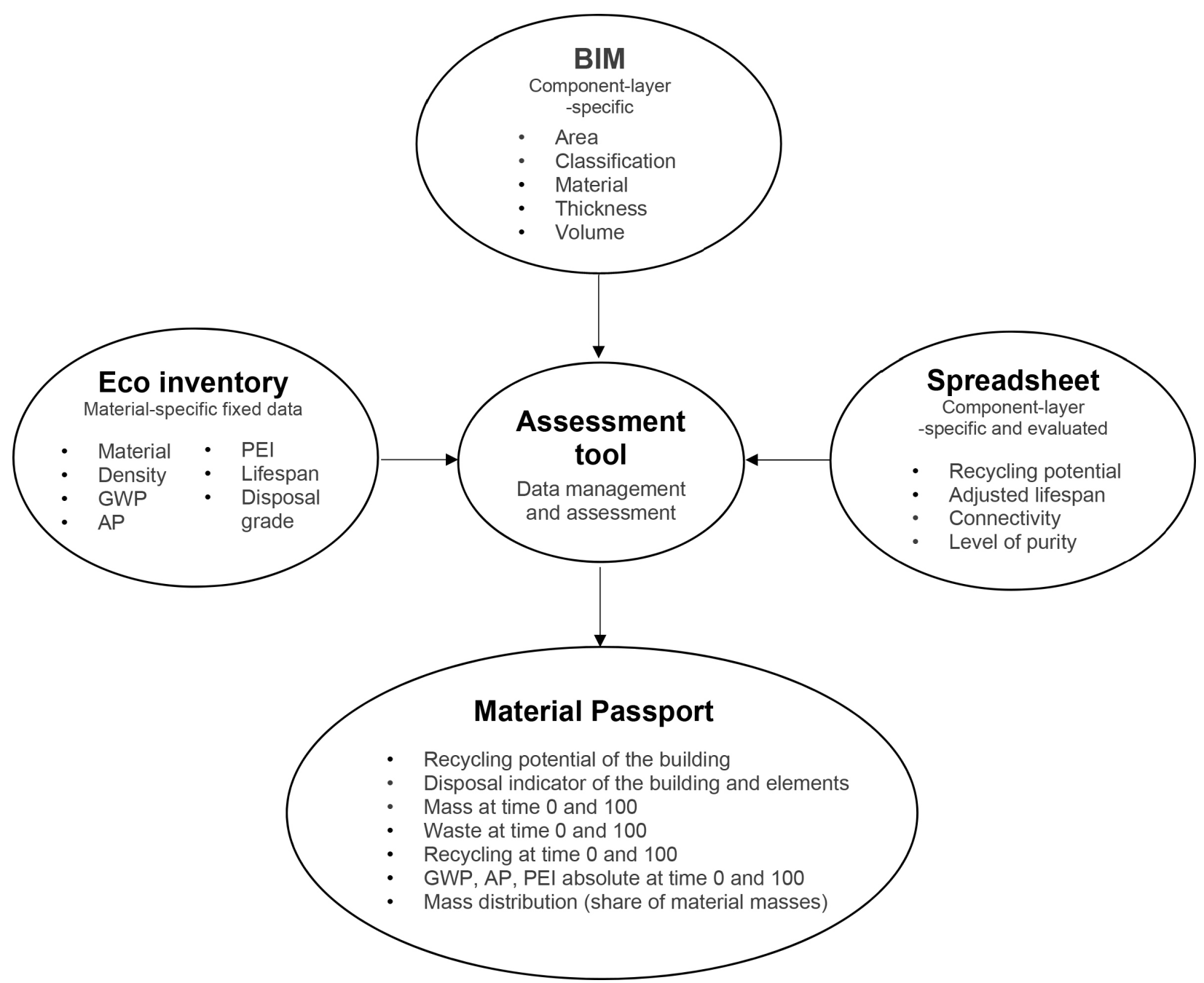

Figure 1 Framework for BIM based MPs.

shown that attributing the exact material properties to the scanned data (point cloud) is difficult, as the standardised or structured material data repositories for this purpose are lacking. Therefore, in order to obtain information-rich BIM-models, providing comprehensive knowledge base including both geometry and parametric attributes, requires further data repositories with structured information on built-in materials according to the building age and typology (historic data) and relevant properties, thus representing one of the major challenges in the achievement of Urban Mining strategies. Regarding the assessment of technology-potentials and usability for achievement of overall CE goals, we conclude that GPR technology for material capturing and modelling via semi-automatic Scan to BIM process for generation of information-rich as-built BIM-model from a point cloud is possible, but requires significant resources and efforts, which are still not feasible in the current practice.

Further, a gamification-based concept for automatic maintenance of BIM-models throughout the life cycle was developed and tested. This gamification concept allows assessment of the structural changes or changes of building elements (users take photo via smartphone, which is uploaded in the photogrammetric as-built BIM within the gamification platform) and of user behaviour (such as open windows or lighting). User participation thus enables both reduction of energy consumption together with the automated update of both the digital twin and MP by embedding of new building elements or deleting of the demolished ones. The gamification concept was well accepted by the 


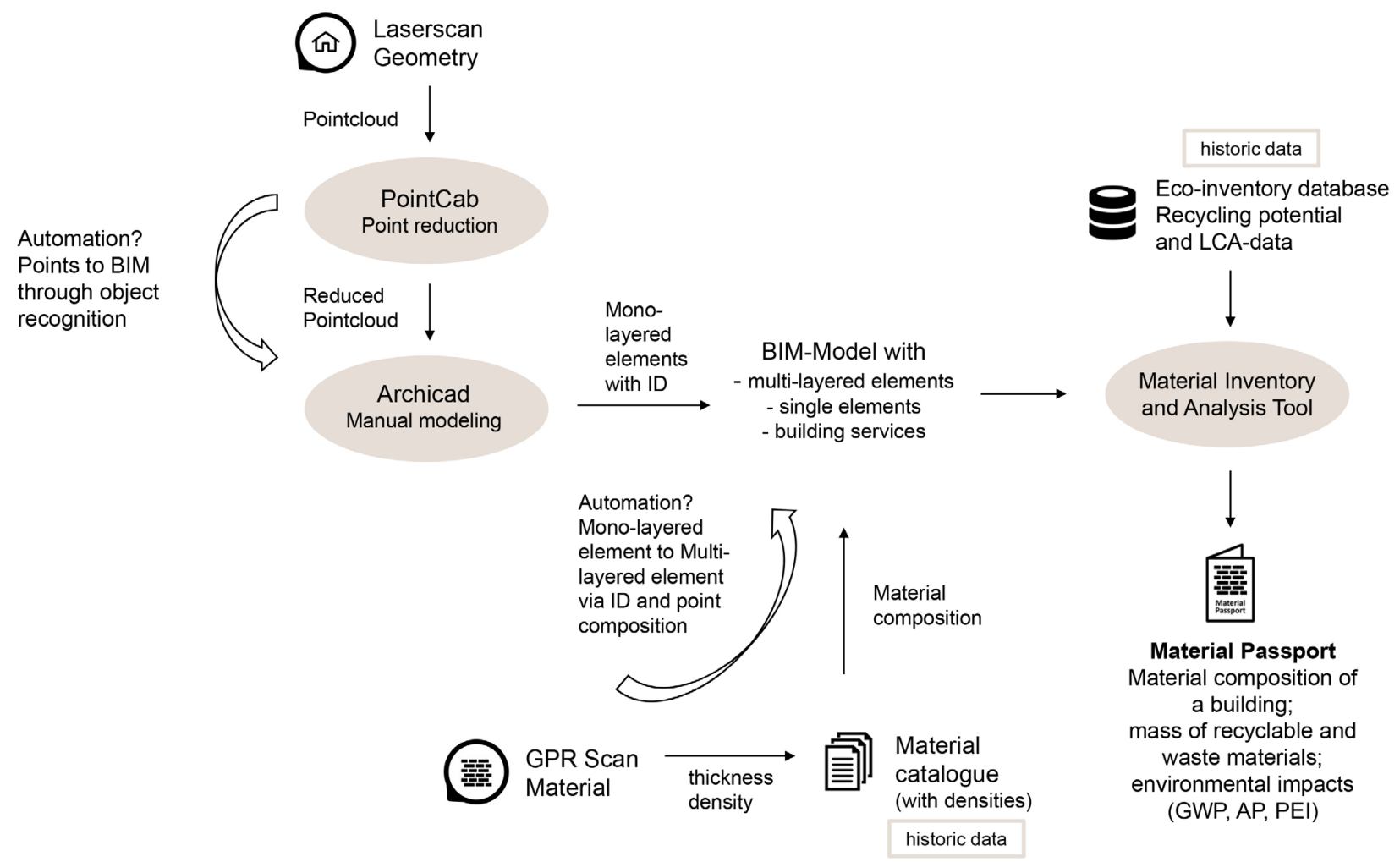

Figure 2 Framework for coupling of digital tools for semi-automatic geometry and material assessment of existing stocks.

users, and obtained data was successfully embedded in the model, the concept displaying both high potential as well as usability in delivering useful information for the creation of a material cadaster as well as for the assessment of the material value of a building at the end of the life cycle.

\section{Intra-firm digital ecosystem: Study of a Design and Planning Company (DPC)}

In order to identify potentials of digital technologies and tools in the AEC practice, regarding a) an intrafirm digital ecosystem, and b) life cycle oriented design and planning for enhancement of $\mathrm{CE}$ in construction, we conducted a case study (Inmann, 2019).

Nearly every planning firm faces problems of a lack of productivity and sometimes poor quality. This is often attributed to the lack of innovation as well as to the low level of digitalization in the AEC industry. Especially in terms of interoperability many weak points can still be identified. As these problems are ubiquitous in the AEC industry, there is still great need for action on issues such as increasing interoperability within a company and digitization in general.

Thereby the analysis of the digital ecosystem of a large design, planning and engineering company (DPC), with more than 800 employees and eight offices across Europe, as an early BIM adaptor, was conducted. In particular, this study focuses on possible interfaces between the various tools of the in-house platform, thus achieving a possible improvement in interoperability.

Figure 3 displays the digital ecosystem of the tools and interfaces employed at the DPC. Generally, the application is structured in modelling tools (creation of native, physical models), calculation and analysis tools and additional tools.

As a central platform the BIM authoring tool Autodesk Revit delivers the central model, data, and information for specific domains of Architecture, Structural-, HVAC-, MEP-Engineering, Cost Calculation and Project Management. Next to the BIM Platform Revit there is a number of supporting modelling tools such as Rhino which is used in 


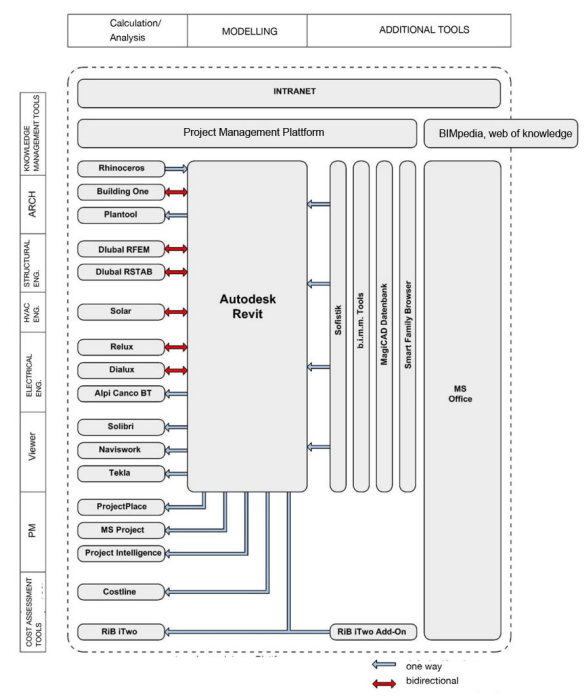

Figure 3 Intra-firm digital ecosystem of the case study DPC.

architectural competitions, delivering wireframe graphics for further processing in higher Level of Development in Revit.

Each of the partaking professional domains also employs domain specific tools for eg, calculation and analysis such as: structural (Dlubal) or energy and light (Solar, Dialux), cost assessment (RIB iTwo) or project management.

General knowledge management tools such as BIMpedia (2019) - the web of knowledge on intra-firm BIM modelling standards, as well as on national and international BIM standards, and the own inter-firm intranet, offer a knowledge base of e.g. standard architectural details, corporate design and layouts, building codes, regulations, and standards; in addition, the company's news site gives insight into new projects or current corporate events.

Through the conducted analysis and interviews with seven experts in the company (structural engineers, architects, BIM manager, CEO of DPC's subsidiary IT company) the following deficits were identified: a large number of employed domain specific software tools next to the central BIM authoring tool require significant effort for creation of proprietary interfaces and workarounds in order to enable smooth data exchange. Most of the data exchange is still a one-way exchange, most of the experts are stressing the necessity for bidirectional exchange in the future. Significant amount of data gets lost in this way, in particular the data on personnel costs (man-hours) and construction costs needs higher level of coupling in order to enable more efficient planning of future projects as well as cost assessment in early design stages.

Despite the relatively high level of digitalization and process integration on the intra-firm level, the concept of synchronous data exchange with further consultants or construction companies (inter-firm) has not been addressed in the digitalization strategy of the DPC. With the upcoming initiative on the BIM-based digital permit by the City of Vienna building authorities "BIM by Environmental Product Declaration (2020)", the issue of inter-firm digital data exchange and integration are gaining significance.

Further, the $\mathrm{CE}$ approach and resources efficiency has not been considered as the scope of work of the DPC yet. However, with upcoming regulations from the European Commission, recycling or material recovery of construction and demolition waste has to account to a minimum of $70 \%$ by weight by 2020 (European Union, 2011). Therefore, the integration of $\mathrm{CE}$ solutions into the existing digital ecosystem of the DPC will be necessary.

\section{Framework for a Digital Platform for CE}

Based on the assessment of the research questions

- Which technologies and to which degree offer potential for $\mathrm{CE}$ in construction?

- How usable are these technologies for the current AEC practice?

- What are the major challenges and obstacles for broader adoption? following conclusions were drawn from the analysis within BIMaterial, SCI BIM and the DPC:

BIM and coupling to the eco-data inventories offers significant potentials for creation and adaption of MPs, thus enhancement of CE; whereas methods such as GPR-based material assessment and semiautomated Point-to-BIM generation are still in the development-stage, thus requiring significant 
efforts and therefore still lack usability for the practice. Gamification has proven as both efficient and usable for maintenance of BIM models in the lifecycle, thus being next to BIM-based MPs an important tool for creation of digital material cadasters. The $\mathrm{CE}$ objectives are still not a priority for the AEC practice; the analysis and optimisation tools are completely lacking within the digital ecosystem, despite the high level of digitalization. The major issue represents the inter- and intra-firm data exchange, thus making the objective of data integration along the value chain, as also observed within BIMaterial as well as SCI_BIM, a major challenge on both the organisational and metaorganisational level.

In order to overcome these difficulties, we propose a conceptual framework for a Digital Platform for Circular Economy in the AEC Industry (DEEP). For this purpose, we apply first a classification proposal of internal and external platforms and their characteristics (Table 1), based on the presented research projects and conceptualised framework. Grounded in the definitions from Gawer and Cusumano (2014), we define internal (company, value chain, product) platforms and external (industry) platforms as follows: Internal platforms are a set of assets or reusable components or technologies organised in a common structure from which a company or project-based organisation can efficiently develop and produce a stream of own (innovative) derivative products, services, or technologies. That firm or organisation, either working by itself or with other stakeholders in the value chain, can build a family of related products, sets of new features, or innovations by deploying these components. External (or industry) platforms, organised as network structures, are products, services or technologies which are developed by one or more firms. They serve as foundations for a larger number of firms ("business ecosystem") for the generation of further complementary or innovative products, services, technologies. Internal platforms and external platforms both provide a foundation of reusable common components or technologies, but they differ in the degree of "openness" to outside firms. The level of openness can vary on a number of dimensions - such as access to interfaces to link to the platform or utilise its capabilities, possibilities of data exchange and sharing in the value chain, the type of rules governing the use of the platform, cost of access, etc.

We see the DPC, BIMaterial and SCI_BIM as forms of internal platforms (on an intra- and interfirm value chain level) and the DEEP framework as an external (industry) platform integrating various stakeholders and data repositories along the AEC value chain for $\mathrm{CE}$, which is featured in Table 1 .

Based on the conducted assessment and analysis of digital tools and data repositories, inter- and inter-firm data exchange processes and stakeholders, under the premise of enhancing $\mathrm{CE}$ in construction, including the analysis from Table 1, we develop a proposal for a Digital Platform for Circular Economy - DEEP (Figure 4) as a digital ecosystem.

As particular data domains for the life cycle, inter- and intra-firm data exchange are identified (Figure 4):

- Institutional Domain: the upcoming digital buildings permit process, which requires bidirectional data exchange, incorporating the digital cadaster available to the planners; digital data exchange standards (such as CEN, BIM ÖNORM etc.), and finally digital repository of national building codes and standards.

- Industry and Manufacturer Domain: addresses the data delivered by the industry, such as manufacturer product declarations, BIM Objects etc.

- CE Public policy Domain: ie, environmental agencies or regulating bodies, which deliver eco-inventories, generic environmental declarations, waste, and recycling data.

- AEC companies: with their intra-firm platforms.

- Users: data collected through users, or user behaviour, regarding material use and energy performance.

Thereby data availability, reliability and accessibility play a crucial role; for which a consent 


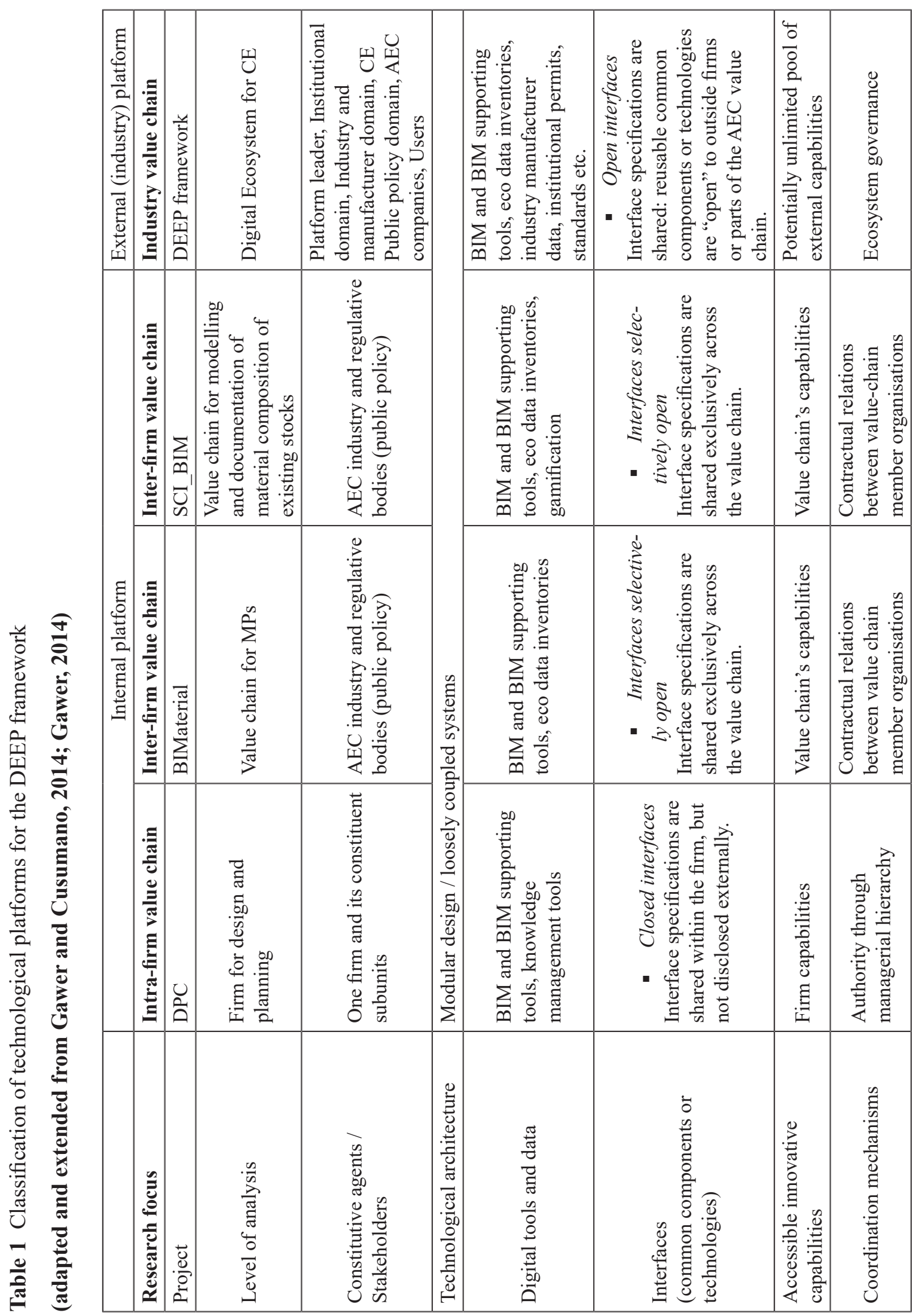

Engineering Project Organization Journal

(C) 2020 Engineering Project Organization Society www.epossociety.org 


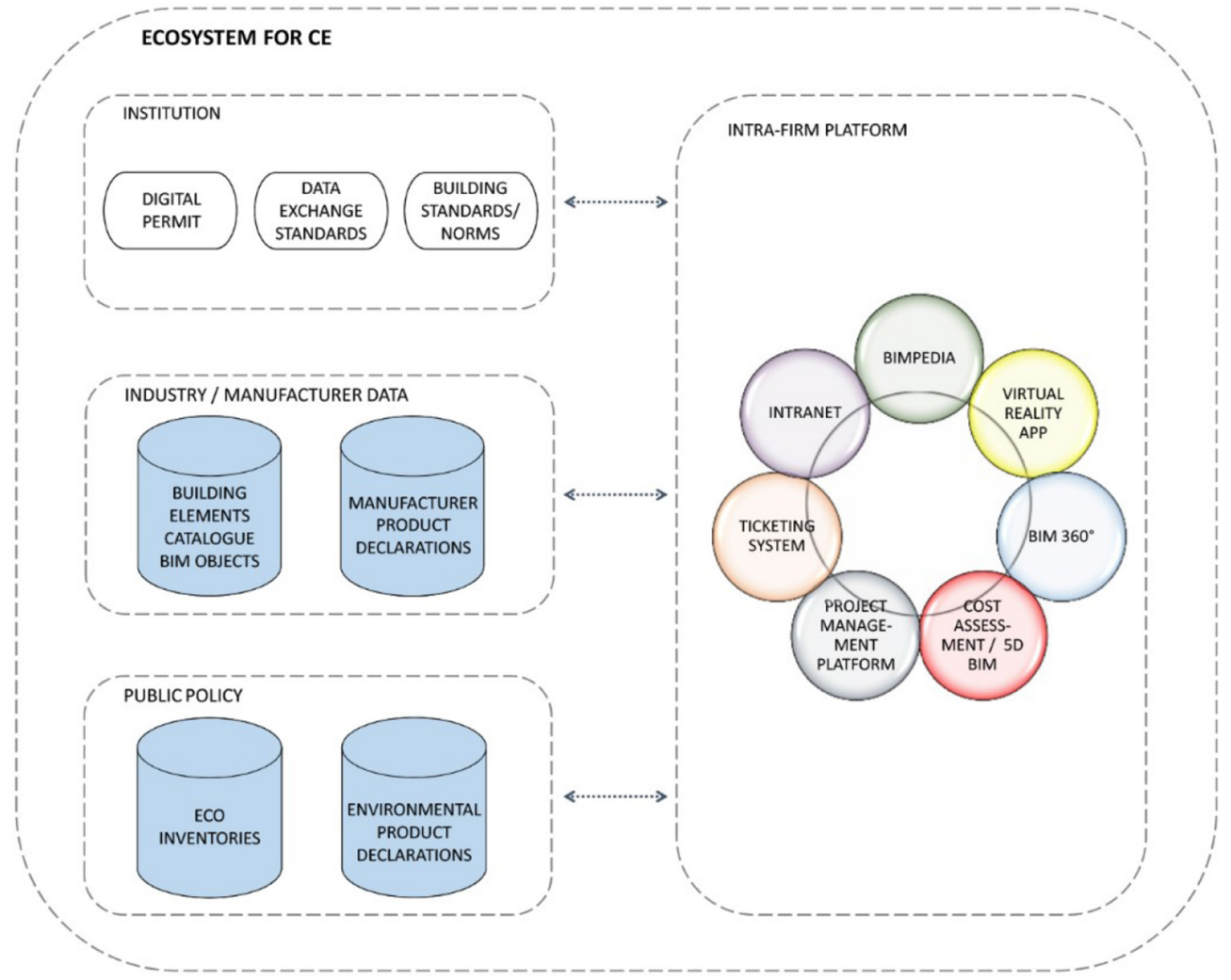

Figure 4 Proposal of a platform as a digital ecosystem enabling life cycle inter- and intra-firm data exchange and integration of CE.

and commitment of all partaking stakeholders is needed.

In conclusion, in the framework for DEEP, coupling and integration of eco-repository data, manufacturers' environmental product declaration and BIM relevant objects properties, as well as digitised public policy regulations, need to be coordinated in a digital ecosystem which allows and supports data exchange along the life cycle, due to its flat and open structure.

\section{Discussion and conclusion}

With the rapid global growth of urban conglomerations and related increased construction activity (UN DESA, 2015) the scarceness of resources, as well as upcoming of waste is becoming an urgent problem for the construction industry. Thereby the implementation of circular economy objectives - Reduce, Recycle, Reuse, Recover - in construction, which counts as one of the major consumers of material resources as well as an originator of solid waste (SERI, 2013), is becoming increasingly important and urgent within the European Union policy.

We hypothesise that digital technologies offer significant potential for realisation of $\mathrm{CE}$ aims in construction, through the enabling of:

- assessment, modelling, and optimisation of resources flows along the life cycle,

- provision of data access

- creating added value to the stakeholders through creation of new business models

In order to verify our hypothesis, we explored potentials of various digital technologies, their usability in practice as well major challenges in the wide adoption of these technologies and thus realisation of $\mathrm{CE}$ objectives in construction using ongoing research projects.

We concluded that new tools have varying degrees of both potentials as well as usability 
regarding assessment, modelling and optimisation of material resources - BIM is certainly a tool that is already well established, where as GPR and automation procedures such as Scan to BIM have high potential, but need further development. Data access, for which standardisation and open interfaces are needed, as well as data integration along the value chain represent one of the greatest challenges requiring commitment of the whole AEC community.

In that context digital technologies are drivers of change in traditional processes and value chains in the industry. Their "disruptive nature" leads to the creation of new business models and generates the necessity for new domain-specific consultancies such as in the area of MPs or BIM for life cycle, which our presented research projects have demonstrated. In addition, the rising complexity of projects and project-based organisations in AEC in regard to the number of involved stakeholders and institutions, technical or digital domain-specific requirements, supplychains and manufacturing procedures, outsourcing of services, policy regulations etc., put platforms (digital ecosystems) into the spotlight as integrative solutions for collaboration and collective added value creation. These platforms, integrated into the value chain as part of the company's business model, nowadays fulfil different scopes in projects in AEC (documentation, exchange of data and e-services, collaboration etc.) and assume diverse organisational structures. In these new business models, organisational and project goals co-align with the scope of the platform, whereas the use of digital technology supports and serves the objective of the company (or organisation). Nevertheless, platforms aiming at collaboration for collective value creation and knowledge management along the value chain in AEC - from cradle to grave - are still missing.

With the framework of DEEP we wanted to address the complexity and current industry-wide challenges concerning assessment, modelling and optimisation of resources flows along the life cycle in AEC, in co-alignment with the implementation of digital technologies. The external (industry) platform for the circular economy would offer structured and open data exchange formats for the enhancement of productive processes, including improved engineering, procurement and supply chain management. This would result in the creation of new business models and thus innovation in the AEC industry. This platform for the AEC industry would increase productivity and optimise material usage in the circular economy - from cradle to grave, foster mutual learning and coordination, identify knowledge and intervention gaps.

\section{Acknowledgments}

Research Projects: BIMaterial: Process-Design for BIM based material building pass, Grant No.: 850049 as well as SCI_BIM: Scanning and data capturing for Integrated Resources and Energy Assessment using Building Information Modelling, Grant No. 867314 are both funded by the Federal Ministry Republic of Austria: Transport, Innovation and Technology through the Austrian Research Promotion Agency (FFG).

\section{References}

Andersen, M.S. (2007), "An introductory note on the environmental economics of the circular economy", Sustainability Science, Vol. 2 No. 1, pp. 133-140. 10.1007/s11625-006-0013-6

Baccini, P. and Brunner, P.H. (2012), Metabolism of the anthroposphere: analysis, evaluation, design. Cambridge: MIT Press.

Baldwin, C. and Woodard, C.J. (2009), "Platforms, Markets and Innovation". In: Gawer A, ed, The Architecture of Platforms: A unified view. Cheltenham: Edward Elgar.

BAMB - Buildings as Material Banks. (2016), available at: https://www.bamb2020.eu [accessed March 2019].

Basbagill, J., Flager, F., Lepech, M. and Fischer, M. (2013), "Application of life-cycle assessment to early stage building design for reduced embodied environmental impacts", Building and Environment, Vol. 60, pp. 81-92. 10.1016/j.buildenv.2012.11.009

Bazjanac, V. (2004), "Virtual building environments (VBE)-applying information modeling to buildings". In: Dikbas A, Scherer R, ed, eWork and eBusiness in Architecture Engineering and Construction. London, UK: Taylor and Francis.

BIMobject. (2019), available at: https://www.bimobject.com/de [accessed 02 July 2019].

BIMpedia. (2019), available at: https://www.bimpedia. eu/ [accessed 02 July 2019]. 
Brunner, P.H. (2011), "Urban mining a contribution to Reindustrializing the City", Journal of Industrial Ecology, Vol. 15 No. 3, pp. 339-341. 10.1111/j.1530-9290.2011.00345.x

buildingSMART. (2019), available at: https://www. buildingsmart.org/ [accessed 02 July 2019].

COM (European Commission). (2015), "Closing the Loop - An EU Action Plan for the Circular Economy", Communication from the Commission to the European Parliament. The Council, the European Economic and Social Committee and the Committee of the Regions. .

Cossu, R. Williams, I.D. and Mining, U. (2015), "Urban mining: concepts, terminology, challenges", Waste Management, Vol. 45, pp. 1-3. 10.1016/j. wasman.2015.09.040

Eastman, C., Teicholz, P., Sacks, R. and Liston, K. (2011), BIM handbook: A guide to building information modeling for owners, managers, designers, engineers and contractors. New Jersey: John Wiley $\&$ Sons.

EMAF - Ellen MacArthur Foundation. (2013), "Towards the circular economy", Journal of industrial ecology, Vol. 2, pp. 23-44.

Environmental Product Declaration. (2020), "The international EPD system", available at: https://www. environdec.com/.

European Union. (2011), “Commission Decision, establishing rules and calculation methods for verifying compliance with the targets set in Article 11(2) of Directive 2008/98/ EC of the European Parliament and of the Council", Off. J. Eur. Union.

Frosch, R.A. and Gallopoulos, N.E. (1989), "Strategies for manufacturing", Scientific American, Vol. 261 No. 3, pp. 144-152. 10.1038/scientificamerican0989-144

Gawer, A. (2014), "Bridging differing perspectives on technological platforms: toward an integrative framework", Research Policy, Vol. 43 No. 7, pp. 1239-1249. 10.1016/j.respol.2014.03.006

Gawer, A. and Cusumano, M.A. (2014), "Industry platforms and ecosystem innovation", Journal of Product Innovation Management, Vol. 31 No. 3, pp. 417-433. 10.1111/jpim.12105

Goulding, J.S., Rahimian, F.P. and Wang, X. (2014), "Virtual reality-based cloud Bim platform for integrated AEC projects", Journal of Information Technology in Construction, Vol. 19, pp. 308-325.

Grilo, A. and Jardim-Goncalves, R. (2010), "Value proposition on interoperability of Bim and collaborative working environments", Automation in Construction, Vol. 19 No. 5, pp. 522-530. 10.1016/j. autcon.2009.11.003
Gulati, R., Puranam, P. and Tushman, M. (2012), "Meta-organization design: rethinking design in interorganizational and community contexts", Strategic Management Journal, Vol. 33 No. 6, pp. 571-586. 10.1002/smj.1975

Honic, M. and Kovacic, I. (2019), "Model and Data Management Issues in Integrated Assessment of Existing Building Stocks", Proceedings of 14th International Organization, Technology and Management in Construction Conference held in Zagreb, September 04 - 07, 2019. ISBN 978-953-7686-08-6.

Honic, M., Kovacic, I., Sibenik, G. and Rechberger, H. (2019), "Data- and stakeholder management framework for the implementation of BIM-based material Passports", Journal of Building Engineering, Vol. 23, pp. 341-350. 10.1016/j.jobe.2019.01.017

Inmann, M. (2019), “Optimierung der Planungsprozesse mittels digitalen Plattformen - Fallstudie", Master Thesis, TU Wien, Institut für Interdisziplinäres Bauprozessmanagement", Fachbereich Industriebau und interdisziplinäre Bauplanung.

International Organization for Standardization. (2006a), "ISO 14040 - Environmental Management - Life Cycle Assessment - Principles and Framework".

International Organization for Standardization. (2006b), "ISO 14025:2006 - Environmental labels and declarations - Type III environmental declarations - Principles and procedures".

International Organization for Standardization. (2010), "ISO 29481-1: Building Information Modeling Information Delivery Manual - Part 1: Methodology and Format".

Jacobides, M.G., Cennamo, C. and Gawer, A. (2018), "Towards a theory of ecosystems", Strategic Management Journal, Vol. 39 No. 8, pp. 2255-2276. 10.1002/smj.2904

Jung, Y. and Joo, M. (2011), "Building information modelling (Bim) framework for practical implementation", Automation in Construction, Vol. 20 No. 2, pp. 126-133. 10.1016/j.autcon.2010.09.010

Klinglmair, M. and Fellner, J. (2010), “Urban mining in times of raw material shortage: copper management in Austria during World War I', Journal of industrial ecology, Vol. 14 No. 4, pp. 666-679.

Korhonen, J., Honkasalo, A. and Seppälä, J. (2018), "Circular economy: the concept and its limitations”, Ecological Economics, Vol. 143, pp. 37-46. 10.1016/j.ecolecon.2017.06.041

Kovacic, I. and Honic, M. (2018), "BIMaterial: Process-Design for a BIM-based Material Passport", available at: https://www.industriebau. 
tuwien.ac.at/fileadmin/mediapool-industrie bau/ Diverse/Forschung/BIMaterial_Brosch\%C3\%BCre Kurzversion_englisch.pdf.

Lévy, F. (2011), BIM in small-scale sustainable design. New Jersey: John Wiley \& Sons.

Library, N.B.S. (2019), "National BIM Library", available at: https://www.nationalbimlibrary.com/en/ [accessed 02 July 2019].

Lieder, M. and Rashid, A. (2016), "Towards circular economy implementation: a comprehensive review in context of manufacturing industry", Journal of cleaner production, Vol. 115, pp. 36-51.

Meadows, D.H., Randers, J. and Behrens III, W.W. (1972), The limits to growth: a report to the club of Rome. New York: Universe Book.

ÖKOBAUDAT. (2019), available at: https://www. oekobaudat.de/ [accessed March 2019].

Parker, G.G., Van Alstyne, M.W. and Choudary, S.P. (2016), Platform Revolution: How Networked Markets Are Transforming the Economy and How to Make Them Work for You. New York: WW Norton \& Company.

Prieto-Sandoval, V., Jaca, C. and Ormazabal, M. (2018), "Towards a consensus on the circular economy", Journal of Cleaner Production, Vol. 179, pp. 605-615. 10.1016/j.jclepro.2017.12.224

Rajendran, P. and Gomez, C.P. (2012), "Implementing Bim for waste minimization in the construction industry: a literature review", 2nd International Conference on Management, Malaysia, pp. 557-570.

Rezgui, Y. and Meziane, F. (2005), “A web services implementation of a User-Centered knowledge management platform for the construction industry", International Journal of Intelligent Information Technologies, Vol. 1 No. 4, pp. 1-19. 10.4018/ jiit.2005100101

Sanchez, R. and Mahoney, J.T. (1996), "Modularity, Flexibility and Knowledge Management in Product and Organization Design", Strategic Management Journal, Vol. 17, pp. 63-76.

Selander, L., Henfridsson, O. and Svahn, F. (2013), "Capability search and Redeem across digital ecosystems", Journal of Information Technology, Vol. 28 No. 3, pp. 183-197. 10.1057/jit.2013.14
SERI. (2013), available at: www.materialflows.net [accessed March 2019].

Singh, V., Gu, N. and Wang, X. (2011), "A theoretical framework of a BIM-based multi-disciplinary collaboration platform", Automation in Construction, Vol. 20 No. 2, pp. 134-144. 10.1016/j.autcon.2010.09.011

Soust-Verdaguer, B., Llatas, C. and García-Martínez, A. (2017), "Critical review of bim-based LCA method to buildings", Energy and Buildings, Vol. 136, pp. 110-120. 10.1016/j.enbuild.2016.12.009

UN DESA. (2015), available at: https://www.un.org/ development/desa/publications/world-populationprospects-2015-revision.html [accessed March 2019].

Volk, R., Stengel, J. and Schultmann, F. (2014), "Building information modeling (Bim) for existing buildings - literature review and future needs", Automation in Construction, Vol. 38, pp. 109-127. 10.1016/j.autcon.2013.10.023

WEF - World Economic Forum. (2016), "Can the circular economy transform the world's number one consumer of raw materials?" available at: https:// www.weforum.org/agenda/2 016/05/can-the-circular-economy-transform-the-world-s-number-oneconsumer-of-raw-materials/2016 [accessed March 2019].

WGBC - World Green Building Council. (2016), "Global status report".

Yoo, Y., Henfridsson, O. and Lyytinen, K. (2010), "Research Commentary - The New Organizing Logic of Digital Innovation: An Agenda for Information Systems Research", Information Systems Research, Vol. 21 No. 4, pp. 724-735. 10.1287/ isre. 1100.0322

Zabalza Bribián, I., Valero Capilla, A. Aranda Usón, A, Bribián, I.Z., Capilla, A.V. and Usón, A.A. (2011), "Life cycle assessment of building materials: comparative analysis of energy and environmental impacts and evaluation of the eco-efficiency improvement potential", Building and Environment, Vol. 46 No. 5, pp. 1133-1140. 10.1016/j.buildenv.2010.12.002 